\title{
Comunidades de prática digitais e sustentabilidade da aquicultura na Amazônia brasileira. $O$ caso da rede social on-line WhatsApp "Peixe de Rondônia"
}

\author{
Virtual communities of practice and sustainability of aquaculture in the \\ Brazilian Amazon. The case of the online social network WhatsApp "Peixe \\ de Rondônia"
}

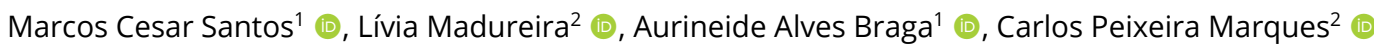

${ }^{1}$ Universidade Federal de Rondônia (UNIR), Porto Velho (RO), Brasil. E-mails: marcoscesar@unir.br; aurineideb@unir.br ${ }^{2}$ Centro de Estudos Transdiciplinares para o Desenvolvimento (CETRAD), Universidade Trás-os-Montes e Alto Douro (UTAD) Vila Real, Portugal. E-mails: Imadurei@utad.pt; cmarques@utad.pt
\end{abstract}

Como citar: Santos, M. C., Madureira, L., Braga, A. A., \& Marques, C. P. (2021). Comunidades de prática digitais e sustentabilidade da aquicultura na Amazônia brasileira. O caso da rede social on-line WhatsApp "Peixe de Rondônia". Revista de Economia e Sociologia Rural, 59(1), e238885. https://doi.org/10.1590/1806-9479.2021.238885

\begin{abstract}
Resumo: Este artigo destaca uma rede de aquicultores na região centro-este da Amazônia brasileira, com base em discussões do grupo WhatsApp "Peixe de Rondônia", entre agosto de 2016 e outubro de 2017, acerca de soluções para superar os desafios ambientais, sociais e econômicos. Para tanto, buscouse verificar a utilidade dessa rede para o compartilhamento de informações com vista à promoção da sustentabilidade do setor, mediante técnicas de análise de rede social e análise de conteúdo na perspectiva exploratória, com apoio computacional dos softwares Gephi e Iramuteq, cujos resultados apontam que a rede total apresenta quatro classes com níveis de interação distintos e complementares e baixa densidade $(0,038)$. A análise de conteúdo demonstrou a existência de cinco clusters de interesse: "mercado", "grupo social", "processos produtivos", "legislação" e "normatização". O cluster "mercado" apresenta robustez quanto à proximidade e à coesão, configurando-se em uma comunidade de prática ativa dos produtores terminadores. Preocupações com sustentabilidades econômica e ecológica foram constatadas, porém verificou-se que a rede não se constitui efetivamente em comunidade de prática, pois não há evidências de que as discussões promovidas no grupo, até o momento, geraram ações reais de contribuição para a sustentabilidade da atividade. As evidências indicam que os atores do grupo, individualmente, possuem interesse na concretização das ações propostas, no entanto constatou-se que ainda são necessárias tomada de conciência e organização coletiva para alcançar objetivos comuns com foco na sustentabilidade do setor.
\end{abstract}

Palavras-chave: Amazônia, aquicultura, comunidade digital de prática, redes sociais on-line (RSO), sustentabilidade.

Abstract: This article highlights a network of aquaculture farmers in the central-eastern region of the Brazilian Amazon based on the discussions of the WhatsApp group "Peixe de Rondônia", between August/2016 and October/2017, about solutions to overcome environmental, social, and economic challenges. To this end, we sought to verify the usefulness of this network for sharing information to promote the sustainability of the sector. Using social network analysis techniques and content analysis in an exploratory perspective, with computational support from Gephi and Iramuteq software, the results show that the total network has four classes with different and complementary levels of interaction and low density (0.038). The content analysis demonstrated the existence of five clusters of interest: "market", "social group", "production processes", "legislation" and "standardization". The "market" cluster is robust in terms of proximity and cohesion, forming a community of active practice for terminating producers. The other classes are related to social components of the network and focus on institutional aspects: topics such as commercial, productive processes, and legal security are discussed. Concerns about economic and ecological sustainability were noted, but it was found that the network is not effectively 
constituted as a community of practice, as there is no evidence that the discussions promoted in the group, so far, have generated real actions to contribute to the sustainability of the activity. The evidence indicates that the group actors, individually, have an interest in the implementation of the proposed actions, however, it was found that there is still a need for awareness and collective organization to achieve common goals focused on the sustainability of the sector.

Keywords: Amazon, aquaculture, digital community of practice, online social networks (RSO), sustainability.

\section{INTRODUÇÃO}

A aquicultura ou piscicultura é uma atividade produtiva que tem atraído investimentos na Amazônia brasileira para a criação de peixes em água doce. O interesse de organizações e indivíduos nessa atividade vem ao encontro das afirmativas da Food and Agriculture Organization (FAO), da Organização das Nações Unidas (ONU), que apontam a aquicultura como uma das formas de produção sustentáveis de proteína animal para consumo humano.

Nessa perspectiva, a Food and Agriculture Organization (2018) indica que a previsão de consumo mundial de alimentos terá acréscimo de 1,4\% ao ano até 2024 , em razão do aumento da população e do crescimento da renda média, principalmente em países em desenvolvimento. As projeções de aumento do consumo per capita entre 2019 e 2024 são de 1,3\%, em países desenvolvidos, e 2,8\%, em países em desenvolvimento. Esse aumento do consumo global traduzir-se-á numa demanda crescente de fontes de proteína animal. Consequentemente, espera-se um acréscimo estimado de 3,8\% na produção de proteína animal no período em referência (Food and Agriculture Organization, 2018). Nesse contexto, é evidente a importância da aquicultura para responder à necessidade crescente de proteína animal para a alimentação humana, com destaque dos países em desenvolvimento.

A expansão da atividade aquícola no centro-oeste da Amazônia brasileira está em consonância com a necessidade do aumento de produção de proteína animal proveniente da aquicultura. $O$ interesse pela atividade nessa região foi motivado pela sua rentabilidade, uma vez que atingiu percentuais de produção a uma média anual de 4,5\% ao ano, na última década, e de 90 mil toneladas de peixes nativos na região, em 2018 (Rondônia, 2019). Assim, a grande expansão dessa atividade na região sugere riscos de insustentabilidade socioecológica (Bush, 2018).

Os sistemas de produção aquícolas são sistemas humanos e naturais que variam conforme o espaço, o tempo e as características das unidades organizacionais de forma similar aos sistemas socioecológicos (SES). Os SES são constituídos por dois subsistemas interligados e interdependentes: o sistema social é um ecossistema em que há riscos de ruptura da homeostase dos sistemas (Ostrom, 2009; Von Bertalanffy, 1977). Outros autores salientam que os SES são dependentes entre si, coevoluem e interagem em vários níveis e escalas em busca do desenvolvimento e do equilíbrio sustentável. Nesse contexto, assume-se que a sustentabilidade da aquicultura deve ser entendida como um processo dinâmico que procura equilibrar as tensões entre benefícios, custos privados e coletivos, por meio da promoção de SES geradores de renda, todavia capazes de salvaguardar os recursos naturais e de garantir o bem-estar futuro das comunidades locais (Food and Agriculture Oraganization of the United Nations, 2016).

As preocupações com a sustentabilidade ambiental da aquicultura são notáveis, como demonstra o forte nível de regulação ambiental da atividade, em particular no contexto da União Europeia (European Comission, 2015). No Brasil, estudos desenvolvidos na região amazônica evidenciam problemas de sustentabilidade ambiental generalizados na atividade aquícola, a exemplo dos efluentes de tanques de produção lançados nos cursos de água. Ademais, outros problemas como escavações de reservatórios com grandes áreas alagadas que envolvem desvios em cursos de rios, poluição das águas em lagos naturais e alterações irreversíveis nos ecossistemas e na biodiversidade também são perceptíveis (Inman et al., 2018; Soares et al., 2018; Oliveira, 2009).

Em conformidade com Borges \& Lansink (2016), a intensidade da ação humana na exploração dos recursos naturais, ou seja, o sistema social, em novas fronteiras agrícolas como se apresenta na região centro-oeste da Amazônia brasileira, pode, a partir da tomada de decisão dos interessados na aquicultura, com base nas informações disponíveis, 
impossibilitar a sustentabilidade da atividade em longo prazo, ou seja, pôr em risco o ecossistema que sustenta a atividade aquícola (Brabo et al., 2016; Bert, 2007).

Para suprir as necessidades de informação, os aquicultores da região organizam-se em associações, cooperativas ou grupos de interesses para fortalecer o setor produtivo com compartilhamento, transferência e apoio para dinamizar a atividade mediante o uso de informações (Turner et al., 2017). O envolvimento nessas redes, onde múltiplos processos interagem e os atores envolvidos desenvolvem a capacidade de análise conjunta em busca de solução, é percepcionado pelos agentes como uma forma de conseguir a tradução da informação em conhecimento (Ingram et al., 2018). Entre os diversos meios de comunicação existentes, as redes sociais on-line (RSOs), vêm sendo utilizadas como canais de comunicação, troca de informações e partilha de conhecimento (Grabowicz et al., 2012; Recuero, 2006).

O crescimento imparável da aquicultura na região centro-oeste da Amazônia brasileira e a crescente preocupação de cientistas e da sociedade em geral com a sustentabilidade ambiental da atividade constituem a principal motivação para a investigação apresentada neste artigo. Procurou-se perceber, por meio da análise das mensagens trocadas por um grupo de usuários do aplicativo WhatsApp, designado Peixe de Rondônia, a maior rede digital identificada na região, como são perspetivadas e discutidas as questões relacionadas com a sustentabilidade da atividade, em particular na sua dimensão ambiental. Essa comunidade de prática digital que utiliza o aplicativo WhatsApp, muito popular no Brasil, foi constituída em 2016 e conta, atualmente, com cerca 260 usuários, incluindo aquicultores, fornecedores, compradores, mas igualmente agentes institucionais ligados à regulação do setor.

Objetiva-se com este artigo apresentar uma abordagem original e inédita para a análise da ação de redes sociais na aquicultura, aplicando metodologias de análise de redes sociais e de análise de conteúdo. Pretende-se analisar a rede como comunidade digital de prática e caracterizá-la como rede de aconselhamento na dinâmica da partilha do conhecimento e informação, em especial com o uso da ferramenta tecnológica do aplicativo WhatsApp.

Neste artigo, propõe-se a análise de uma questão de investigação com grande relevância, a de saber em que medida e como os aquicultores e demais interessados na aquicultura da região centro-oeste da Amazônia brasileira perspetivam e objetivam a sustentabilidade da atividade mediante a análise das informações que partilham em uma rede digital que suporta a respectiva comunidade de prática. Adicionalmente, a decomposição e a identificação das características dessa rede social ativa na aquicultura permitirão avaliar em que medida esta se constitui em veículo de coesão e de partilha de informações e conhecimento entre os atores.

Deste modo, o presente artigo apresenta uma contribuição, que julgamos pertinente e relevante, para avaliar em que medida se poderão propor esse tipo de redes digitais como suporte de comunidades de prática capazes de promover o crescimento econômico, o social e o ambientalmente sustentável diante da expansão da aquicultura na região que sugere riscos de insustentabilidade socioecológica.

Tal contribuição poder-se-á estender à aquicultura em outras regiões e, eventualmente, a outras atividades que envolvam SES e onde a partilha de informações e conhecimento possa ser facilitada por comunidades de prática com suporte digital.

Para o cumprimento de seu objetivo, este trabalho está estruturado em cinco partes: a primeira traz a introdução com suas justificativas e apresenta os objetivos e relevância da pesquisa. Na segunda, apresentam-se as bases teóricas da rede digital e como são objeto de análise por meio dos métodos da análise de redes sociais e análise de conteúdo. Na terceira parte do artigo, expõem-se os procedimentos metodológicos, a caracterização da rede e sua constituição, bem como a aplicação dos métodos utilizados para sua análise. Na quarta parte, apresentam-se resultados e discussões dos achados no estudo. Por último, apresentam-se algumas conclusões gerais.

\section{FUNDAMENTAÇÃO TEÓRICA}

Informação e redes são conceitos transversais que encontram abrigo de passagem em diferentes domínios de conhecimento, mídias, níveis sociais ou comunidades profissionais. O intercâmbio, o fluxo, o uso e a apropriação de informações dependem, por sua vez, da capacidade de indivíduos, grupos e organizações se associarem para o aprendizado, o compartilhamento, a 
mobilização e a ação coletiva em redes sociais (Marteleto, 2010). As redes de cooperação técnica informais se apresentam também como uma solução na aquicultura para a canalização de informações e conhecimento visando à inovação nesse setor (Resende, 2009).

Redes sociais são também fenômenos de agregação humana que visam reunir ou aproximar pessoas em torno de interesses comuns (Fernandes et al., 2016). A corrente teórica da Nova Sociologia Econômica, marcada por Mark Granovetter, na década de 1970, adotou o conceito denominado embeddedness, caracterizado pela força dos laços fracos, cujas relações sociais imersas em redes possuem as características que controlam as expectativas e o modo de agir dos elementos, sendo elas: a troca de informação, a confiança e a resolução conjunta de problemas (Maciel et al., 2019; Staevie, 2017).

Scott \& Davis (2016) afirmam que a análise de redes sociais é apropriada a dados relacionais, os quais estão enraizados em valores e símbolos culturais, significados, motivos, definições e tipificações, o que envolve, necessariamente, um processo de interpretação apropriado pelo pesquisador. Assim, a subjetividade da ánalise de redes sociais (ARS) de dados relacionais é ampla e necessariamente precedida de base empírica sólida. Do ponto de vista da estrutura da rede sociométrica, o autor demonstra, por meio de gráfico de pontos e linhas, como desenvolver conceitos como distância, direção e densidade, atribuindo-lhes importâncias relativas aos resultados.

Apresentam-se os fatores adjacentes ao processo de troca de informações, ao qual se pretende relacionar os efeitos da comunicação nessa rede, visto que podem influenciar o processo de criação e disseminação do conhecimento. Rieple \& Snijders (2018) observam que redes com menos número de nós podem limitar o processo de criação de novas ideias, só se alterando quando houver maior número e proximidade entre os nós participantes no processo de aprendizagem coletiva. Observam, ainda, que os nós com maior centralidade na rede são aqueles que podem resultar em mais aprendizado, ocasionado pelo acesso direto às informações e à proximidade com os demais interessados, o que gera confiança nas relações, proporcionando à rede condições para a realização da transmissão do conhecimento por meio das relações entre os atores.

A conceituação de rede apreendida de Souza-Silva \& Schommer (2008) remete-nos às diversas estruturas de redes formadas basicamente por atores sociais com ligações formais e informais. A necessidade de os indivíduos se aproximarem de outros com semelhantes objetivos e causas comuns são basicamente os componentes para a formação de redes mediante relações sociais. Uzzi (1997) e Ahuja et al. (2012) afirmam que as redes de relações pessoais com base na confiança possibilitam alto nível de aprendizagem aos indivíduos nelas inseridos, motivados pela cooperação de maneira que podem tornar-se comunidades de prática.

O uso do aplicativo que forma a figura WhatsApp tem sido alvo de estudos sobre comunidades de prática, que usam a comunicação direta e eficaz proporcionada pela ferramenta sem intermediários. O propósito das comunidades de prática é assegurar que objetivos comuns sejam alcançados e aplicados de forma compartilhada. A interação dos membros dessa rede determina a ação da "teia de influenciadores na prática", ao proporcionar um ambiente de inter-relação construtiva de conhecimento partilhado (Dolinska \& D'Aquino, 2016), como ferramenta onipresente, permitindo que as pessoas compartilhem facilmente, por meio de diversos aplicativos, texto, imagens e arquivos de áudio e vídeo (Rosenfeld et al., 2018), para aprendizagem conjunta e geração de novas soluções mais integradas, cruciais para que a atividade se torne sustentável e resiliente (Šūmane et al., 2018). Pode, ainda, representar um canal de informação recíproca, atualização de informes técnicos e dados financeiros da atividade, bem como desempenhar o papel de nivelamento de preocupações em geral, inclusive sobre ações para a sustentabilidade da atividade (Silva \& Zen, 2014).

\section{MATERIAIS E MÉTODOS}

Optou-se por analisar a rede por meio de dois métodos distintos: análise de redes sociais (ARS) e análise de conteúdo (AC). Adotou-se, assim, uma metodologia qualiquantitativa (Schneider \& Sachs, 2017), pois aborda a ARS formada pelos aquicultores e interessados em ambos os aspectos: qualitatitiva, por meio da AC exploratória com auxílio computacional 
(Skalski \& Neuendorf, 2017), e quantitativamente, pela análise da relação dos elementos que compõem a rede (nós e laços), suas ligações, nível de densidade e representações físicas (Recuero, 2014).

A ARS apoia-se basicamente em estatísticas que medem as relações dos nós que compõem a rede. A teoria dos grafos é o apoio técnico para determinar essas medidas, indicando as características peculiares de cada conjunto de nós e suas ligações (ou arestas). Por meio da utilização de matrizes que representam as relações numericamente (formais ou informais, conversações etc.), estas possibilitam que as conexões que caracterizam a rede possam ser apresentadas em forma de gráfico (Crossley et al., 2009). A ARS, que se inicia com a técnica sociométrica de representar a rede como um gráfico composto de nós (atores) e laços (ligações), demonstra como estes podem ser usados para representar e definir medidas da rede, como distâncias, direção e densidade (Crossley et al., 2009). As demais métricas aplicáveis para identificar as relações diáticas, classificando-as por suas semelhanças, relações sociais, interações e fluxos, têm a intenção de entender como esses diferentes tipos de vínculos afetam um ao outro (Borgatti et al., 2009). É mister esclarecer que os padrões de laços sociais nos quais os atores (nós) estão envolvidos são a motivação da ARS. Nessa análise, diferem das redes sociais no mundo cotidiano (off-line), pois deixam rastros no ciberespaço e podem ser rastreadas (Recuero, 2014; Boyd \& Ellison, 2007), precisamente como foram capturadas e trazidas à análise. A Tabela 1 apresenta uma série de terminologias aplicadas à ARS que necessitam de entendimento.

Tabela 1 - Tabela de definições da terminologia aplicada em ARS

\begin{tabular}{|c|c|}
\hline Termo & Definição \\
\hline Nó (vértice) (node) & $\begin{array}{l}\text { A unidade fundamental de uma rede ou conjunto de atores envolvidos, sejam } \\
\text { estes indivíduos, unidades de trabalho, sejam organizações. }\end{array}$ \\
\hline Laço (aresta) (edges) & $\begin{array}{c}\text { A linha que conecta dois nós. Cada aresta pode ter um peso (importância, } \\
\text { distância etc.) e ser direcionada (com uma direção) ou não direcionada (corre em } \\
\text { ambas as direções). }\end{array}$ \\
\hline Ponte (bridge) & $\begin{array}{c}\text { O único empate entre dois componentes (subgrupos de nós) (por exemplo, uma } \\
\text { aresta que é a única rota entre seus pontos finais). Uma aresta é considerada } \\
\text { uma "ponte local" se sua remoção aumentar a distância entre dois nós para mais } \\
\text { de dois (Marteleto, 2001). }\end{array}$ \\
\hline Densidade (density) & $\begin{array}{l}\text { É o número de links (ligações) atuais dividido pelo número máximo de links } \\
\text { possível. A densidade está sempre entre } 0 \text { e } 1 \text {. Quando o número de links atuais } \\
\text { está próximo do máximo possível, o gráfico é considerado denso, caso contrário, } \\
\text { é considerado esparso. Redes (especialmente as grandes) raramente são densas. }\end{array}$ \\
\hline $\begin{array}{l}\text { Centralidade do grau } \\
\text { (degree centrality) }\end{array}$ & $\begin{array}{l}\text { O número de arestas incidentes em um determinado nó. Os nós com alto grau } \\
\text { (mais conexões com os outros) têm mais probabilidade de ter acesso às } \\
\text { informações e influenciar as decisões dos outros. }\end{array}$ \\
\hline $\begin{array}{l}\text { Centralidade de } \\
\text { proximidade } \\
\text { (closeness centrality) }\end{array}$ & $\begin{array}{l}\text { A soma dos caminhos geodésicos entre um nó e todos os outros nós da rede } \\
\text { (proximidade representa a facilidade de passar/acessar informações entre os nós. } \\
\text { Os nós com alta proximidade podem ter acesso mais rápido e fácil/difusão de } \\
\text { informações e comunicação com outros nós). }\end{array}$ \\
\hline $\begin{array}{l}\text { Centralidade de } \\
\text { intermediação } \\
\text { (betweenness } \\
\text { centrality) }\end{array}$ & $\begin{array}{l}\text { O número de outros vértices que precisam passar por um nó específico para } \\
\text { alcançar seu caminho mais curto (as partes interessadas com alta centralidade de } \\
\text { intermediação atuam como "pontos centrais do fluxo de conhecimento na rede" } \\
\text { (Varanda et al., 2012). Conectam diferentes partes interessadas e geralmente têm } \\
\text { conhecimento multidisciplinar. }\end{array}$ \\
\hline Cliques & $\begin{array}{l}\text { Um subgráfico completo do gráfico original, em que cada nó no subgráfico, está } \\
\text { conectado a todos os outros nós (um clique de três nós forma um triângulo). }\end{array}$ \\
\hline $\begin{array}{l}\text { Centralidade entre } \\
\text { cliques (cross-clique } \\
\text { centrality) }\end{array}$ & $\begin{array}{l}\text { O número de subgrupos dos quais um nó faz parte (um nó que faz parte de } \\
\text { vários subgrupos tem mais probabilidade de se espalhar amplamente e promover } \\
\text { suas ideias). }\end{array}$ \\
\hline $\begin{array}{l}\text { Coesão estrutural } \\
\text { (structural cohesion) }\end{array}$ & $\begin{array}{c}\text { O número mínimo de atores que, se removidos de um grupo, desconectariam o } \\
\text { grupo (Zattar et al., 2017). }\end{array}$ \\
\hline
\end{tabular}

Fonte: elaboração própria baseada nos autores citados no texto. 
O segundo componente da abordagem metodológica adotada enfrenta o problema descrito por McMillan (2000), no tocante às dificuldades para aplicar o "microscópio" da análise de conteúdo ao "alvo móvel" da world wide web (www), diante do grande volume de conteúdo gerado pelos usuários, classificados como big data, que se apresentam em frequente evolução. A utilização de métodos híbridos combinando métodos manuais e análises de texto por computador na análise de conteúdo, com o rigor sistemático e conhecimento contextual descritos por Bardin (1977) e a eficiência dos métodos computacionais, é proposta por Neuendorf e Skalski (2010). A AC, em uma perspectiva exploratória, classifica e verifica os conteúdos lexicais das mensagens que apoiam os atores na interação dos diferentes grupos internos de uma rede digital representados (Skalski \& Neuendorf, 2017).

O software selecionado para a implementação da AC foi o IRAMUTEQ (Interface de R pour les Analyses Multidimensionnelles de Textes et de Questionnaires), na sua versão 0.7 alpha 2, por apresentar resultados estatísticos textuais mensuráveis e úteis à análise que se propõe, sem, contudo, limitar as leituras dos resultados apontados pelo programa, uma vez que cabe aos pesquisadores o aprofundamento no trabalho de interpretação entre as análises empíricas e os conceitos (Silva, 2019; Salviati, 2017; Camargo \& Justo, 2013a).

\subsection{A rede objeto de estudo}

A rede em estudo pode ser caracterizada, a princípio, como uma rede social on-line, ancorada no aplicativo de internet WhatsApp. Sua constituição se deu em março de 2016, com a iniciativa de produtores aquicultores para a criação do grupo "Peixe de Rondônia". Tal grupo elegeu a ferramenta para aproximar os aquicultores e possibilitar a troca de informações de forma ágil e eficaz relativas ao mercado do peixe e conhecimentos que envolvem a atividade. O grupo cresceu de forma rápida e, com adesões a convite dos pioneiros, estendeu-se a novos integrantes, contando, em outubro de 2017, com 236 membros inscritos.

A rede representada pelo grupo "Peixe de Rondônia" é composta de produtores de peixes, comerciantes a montante e a jusante dos tanques de produção, estudiosos da aquicultura, industriais ligados aos insumos e ao produto final, representantes de órgãos institucionais que atuam na normalização das atividades, elementos representantes do poder público e de bancos, entre outros. As áreas de produção dos aquicultores membros da rede em foco estão majoritariamente na região centro-oeste da Amazônia Legal Brasileira, no estado de Rondônia, conforme mostra a Figura 1.

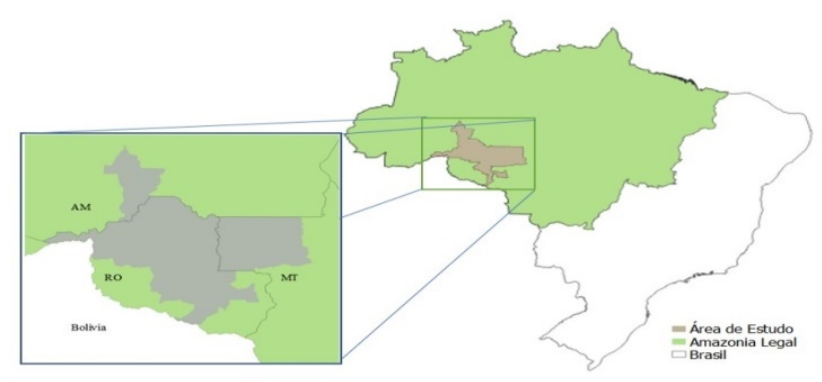

Figura 1 - Mapa da região do estudo. Fonte: Instituto Brasileiro de Geografia e Estatística (2019).

A escolha da rede em foco justifica-se pelo fato de o grupo que a compõe ser o mais extenso em número de participantes locais, bem como em diversidade de representação na cadeia produtiva da aquicultura. Constatou-se que, na época da definição do estudo, havia outros dois grupos utilizando a plataforma WhatsApp com objetivos similares, porém ambos detinham um pequeno número de participantes e alguns deles também faziam parte do grupo selecionado. 


\subsection{Material de análise}

Os materiais analisados são os dados partilhados na rede e as conversas digitadas e trocadas entre os atores do grupo por meio da internet. Previamente à captura do conteúdo das mensagens trocadas, em atenção às questões éticas, de direito à privacidade e a fim de preservar a inviolabilidade da identidade pessoal dos atores, foram tomadas as providências necessárias, como: primeiramente, um dos autores foi convidado pelo administrador a participar do grupo "Peixe de Rondônia" na condição de pesquisador e, após inteirar-se da dinâmica das discussões, informou ao grupo, por intermédio de texto, a intenção de capturar as mensagens trocadas para analisá-las objetivando identificar os conteúdos discutidos, em especial aqueles relacionados à sustentabilidade da aquicultura na região. Em seguida, descreveram-se as técnicas de captura e análises que seriam utilizadas para alcançá-los. Além disso, esclareceu-se que os atores teriam a identidade pessoal preservada e, caso algum participante não autorizasse, suas mensagens individuais poderiam ser retiradas do texto. Então, apresentou-se o pedido de autorização prévia a todos para a realização da captura das mensagens e o consentimento para participação da pesquisa, o que foi de pronto aceito por aqueles que responderam ao questionamento, não havendo, portanto, quando se iniciou a operacionalização, nenhuma manifestação contrária ao pleito.

Os dados analisados pelo presente artigo são as conversas digitadas e trocadas entre os atores do grupo por meio da internet, ou seja, textos extraídos do aplicativo WhatsApp no período compreendido entre $1^{\circ}$ de agosto de 2016 e 30 de outubro de 2017. O ficheiro inicial continha 2.925 mensagens postadas, com 251.684 formas ou palavras, as quais foram copiadas do aplicativo WhatsApp para o programa Microsoft Excel, em que foram identificados os atores (codificados) e classificadas as mensagens. Posteriormente, foram transferidas ao processador de textos Microsoft Word. Após a leitura dos textos, realizou-se a primeira interferência de limpeza nos seus conteúdos, excluindo-se os aglomerados de palavras, imagens, filmes, sinais e emojis considerados inócuos aos objetivos do estudo, bem como expressões de saudações, sinais de aprovação/reprovação/adeus, restando para análise 1.387 postagens, contendo 196.001 formas ou palavras. Nessa primeira análise, constatou-se que somente 220 membros dos 236 inscritos no grupo participaram efetivamente dessa troca de mensagens.

Para AC, realizaram-se leituras do material bruto composto de textos extraídos das mensagens partilhadas em grupo. Essa verificação prévia dos dados teve como finalidade não somente a identificação do conjunto textual que se pretendia analisar, com vista à codificação dos índices, mas também, em consonância com a formulação do objetivo, definir a dimensão e a direção das análises (Skalski \& Neuendorf, 2017). Neste estudo, buscavam-se evidências, segundo a AC das mensagens torcadas, que nos permitissem inferir sobre as perceções e atuações dos aquicultores ligadas à sustentabilidade da aquicultura.

O material composto de textos produzidos coletivamente e transposto para o programa Microsoft Excel foi analisado, classificado e agrupado em segmentos de texto (ST) com um máximo de três linhas, de acordo com os temas identificados que predominavam nas conversas. Foram eliminadas partes textuais desnecessárias à categorização e à codificação dos elementos constitutivos, tornando o material efetivamente explorável pelas técnicas de análise textual sobre o corpus construído nos moldes requeridos pelo software IRAMUTEQ (Camargo \& Justo, 2013a).

Os dados foram organizados por ordem cronológica, observando-se data e hora conforme a sequência real das trocas de mensagens entre os atores do grupo, os quais foram identificados segundo sua atividade profissional no contexto da discussão. Para garantir a anomização dos dados, os atores foram identificados por códigos alfanuméricos que os individualizavam perante os demais e classificavam-nos em grupos, categorias e subcategorias de profissionais para subsidiar as análises computacionais e posicioná-los no contexto da aquicultura (Tabela 2). 
Tabela 2 - Categorias e subcategorias dos membros da rede "Peixe de Rondônia"

\begin{tabular}{|c|c|c|c|}
\hline $\begin{array}{l}\text { Categoria dos } \\
\text { atores/código }\end{array}$ & $\begin{array}{l}\text { Subcategorias } \\
\text { profissional/código }\end{array}$ & $\begin{array}{l}\text { Número } \\
\text { de atores }\end{array}$ & $\begin{array}{c}\text { Descrição da atividade da categoria } \\
\text { profissional }\end{array}$ \\
\hline $\begin{array}{c}\text { Pesquisa e } \\
\text { desenvolvimento }\end{array}$ & $\begin{array}{l}\text { Centros técnicos } \\
\text { especializados/CcE }\end{array}$ & 3 & $\begin{array}{l}\text { Profissionais especializados que atuam na } \\
\text { assistência técnica da aquicultura - apoio de } \\
\text { campo. }\end{array}$ \\
\hline \multirow[t]{4}{*}{$\begin{array}{l}\text { da comunidade } \\
\text { científica/Cc }\end{array}$} & $\begin{array}{l}\text { CcG - Centros } \\
\text { técnicos } \\
\text { governamentais }\end{array}$ & 2 & $\begin{array}{l}\text { Profissionais e funcionários públicos que } \\
\text { atuam na área técnica da aquicultura e apoio } \\
\text { de campo. }\end{array}$ \\
\hline & CcU - Universidades & 2 & $\begin{array}{c}\text { Cientistas e estudiosos na área de } \\
\text { aquicultura. }\end{array}$ \\
\hline & Subtotal & 7 & \\
\hline & Ctl - Intermediários & 11 & $\begin{array}{c}\text { Compradores e revendedores de peixes em } \\
\text { geral. }\end{array}$ \\
\hline \multirow[t]{3}{*}{ Comerciantes/Ct } & $\begin{array}{l}\text { CtT - } \\
\text { Transformadores } \\
\text { industriais }\end{array}$ & 4 & Compradores e industrializadores do peixe. \\
\hline & Subtotal & 15 & \\
\hline & $\begin{array}{l}\text { FiD - Serviços } \\
\text { diversos }\end{array}$ & 2 & $\begin{array}{l}\text { Prestadores de serviços diversos (de pesca, } \\
\text { limpeza, manutenção). }\end{array}$ \\
\hline \multirow{4}{*}{ Fornecedores/Fi } & $\begin{array}{l}\text { FiM - Mão de obra } \\
\text { especializada }\end{array}$ & 1 & $\begin{array}{l}\text { Construtores de tanques, operadores de } \\
\text { máquinas. }\end{array}$ \\
\hline & FiP - Projetista & 1 & $\begin{array}{c}\text { Prestador de serviços de elaboração de } \\
\text { projetos. }\end{array}$ \\
\hline & Subtotal & 4 & \\
\hline & $\begin{array}{l}\text { IdE - Equipamentos e } \\
\text { máquinas }\end{array}$ & 4 & $\begin{array}{c}\text { Fabricantes de equipamentos para } \\
\text { aquicultura. }\end{array}$ \\
\hline \multirow{5}{*}{$\begin{array}{l}\text { Indústria de } \\
\text { equipamentos/Id }\end{array}$} & IdR - Rações & 3 & Fabricantes de ração. \\
\hline & IdT - Tanques-rede & 1 & Fabricantes de tanque-rede. \\
\hline & Subtotal & 8 & \\
\hline & $\begin{array}{l}\text { ItE - Extensão e } \\
\text { conhecimento }\end{array}$ & 7 & $\begin{array}{l}\text { Serviços de assistência técnica e apoio } \\
\text { administrativo/fiscal. }\end{array}$ \\
\hline & ItF - Financeiro & 2 & Representante de bancos/financeiras. \\
\hline \multirow{6}{*}{$\begin{array}{l}\text { Institucional } \\
\text { representando } \\
\text { órgãos oficiais e } \\
\text { privados/lt }\end{array}$} & ItL - Leis e normas & 11 & $\begin{array}{l}\text { Órgãos públicos e privados que atuam como } \\
\text { unidades de controle. }\end{array}$ \\
\hline & $\begin{array}{l}\text { ItP - Políticas } \\
\text { públicas }\end{array}$ & 11 & $\begin{array}{c}\text { Agentes políticos (secretários, deputados, } \\
\text { vereadores). }\end{array}$ \\
\hline & ItS - Associativismo & 8 & $\begin{array}{l}\text { Representante de associações e } \\
\text { cooperativas. }\end{array}$ \\
\hline & Subtotal & 39 & \\
\hline & $\begin{array}{l}\text { PrA - Produtor } \\
\text { alevinos }\end{array}$ & 5 & $\begin{array}{l}\text { Aquele que produz filhotes (alevinos) para } \\
\text { engorda. }\end{array}$ \\
\hline & $\begin{array}{l}\text { PrP - Pequeno } \\
\text { aquicultor }(<5 \text { ha) }\end{array}$ & 25 & $\begin{array}{l}\text { Produtor que explora área menor que } 5 \text { ha } \\
\text { de lâmina d'água. }\end{array}$ \\
\hline \multirow[t]{3}{*}{$\begin{array}{l}\text { Produtor de } \\
\text { peixe/Pr }\end{array}$} & $\begin{array}{l}\text { PrT - Produtor } \\
\text { terminador }\end{array}$ & 128 & Aquele que engorda e comercializa peixes. \\
\hline & Subtotal & 158 & \\
\hline & TOTAL GERAL & 236 & \\
\hline
\end{tabular}

Fonte: elaboração própria (2019). 
Após a identificação dos temas e STs correspondentes, efetuou-se a composição do corpus, que foi organizado e agrupado por conteúdo específico por meio de inferências dos textos e insights obtidos no decurso das leituras, mantendo a identificação dos atores que os inseriram na discussão para efeito da análise pelo software IRAMUTEQ.

Com base nesse software, foi possível realizar análise de dados textuais como estatísticas clássicas que identificam quantidade e frequência de palavras, enumerar palavras únicas (coeficiente de Hapax), identificar palavras de acordo com as classes gramaticais e raiz lexical (lematização), realizar pesquisa de especificidade de grupos, promover a classificação hierárquica descendente e a análise fatorial de correspondência, fazer a análise de similitude e elaborar nuvem de palavras (Salviati, 2017; Kami et al., 2016; Camargo \& Justo, 2013b; Ratinaud \& Marchand, 2012).

Os estudos propostos por Reinert (2008) pressupõem que os vocábulos utilizados em STs representam um traço do ator que o profere e expõe uma intenção ou sentido, com potencial para ser identificado lexicalmente, por meio de cálculos de co-ocorrências e, assim, distinguir classes de palavras constantes em segmentos de textos que as especificam dos demais vocábulos ou que os aproximam.

\section{RESULTADOS E DISCUSSÃO}

\subsection{Análise da estrutura da rede}

Para a ARS, os dados foram coletados em forma de matriz ou sociograma com múltiplas ligações que, submetidos ao programa computacional Gephi versão 0.9.2 (Crossley et al., 2009), expressam a imagem da rede conforme apresentada na Figura 2.

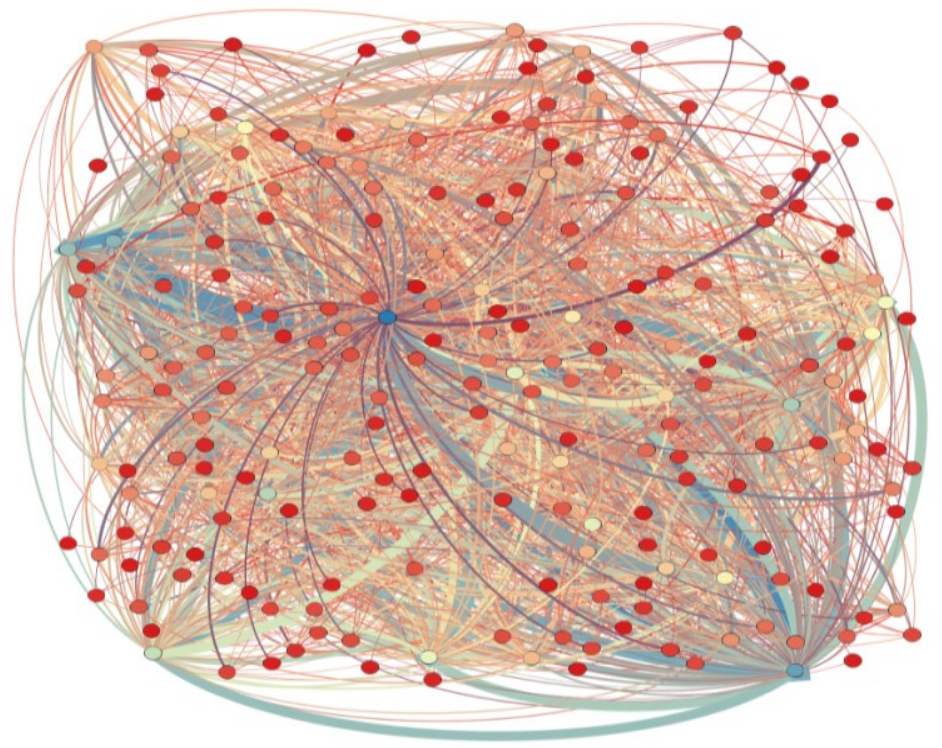

Figura 2 - Rede de relações no grupo WhatsApp “Peixe de Rondônia”. Fonte: elaboração própria com apoio do software Gephi (2019).

A rede foi analisada com base em sua estrutura, na qual se buscou conhecer sua composição segundo o número de atores ou nós, a posição de cada nó, o nível de conexões entre os nós e o nível de inclusão (embeddedness) da estrutura da rede (Granovetter, 1973; Wasserman \& Faust, 1994; Freeman, 2004; Zancan et al., 2012).

A rede pode ser considerada uma rede de baixa densidade quando há um número relativamente grande de atores envolvidos (Zancan et al., 2012). A Tabela 3 demonstra as medidas de análise da rede total grupo "Peixe de Rondônia". 
Tabela 3 - Medidas de análise da rede total - Grupo "Peixe de Rondônia”

\begin{tabular}{cc} 
Medida & Valor \\
Número de atores (nós/nodes) & 220 \\
Número de ligações (laços/edge) & 1.837 \\
Densidade (density) & 0,038 \\
Grau de coesão (reciprocity) & 22,014 \\
Coeficiente de agrupamento (clustering) & 0,351 \\
Centralidade de intermediação (betweenness) & 2,625114155 \\
Centralidade de proximidade (centrality) & 8,350 \\
Modularidade (modularity) & 0,178 \\
\hline
\end{tabular}

Fonte: dados apurados pelo software Gephi versão 0.9.2 (2019).

Recuero (2014), em consonância com a maioria dos autores que estudam a ARS, informa que o tamanho de uma rede consiste no total de ligações efetivas ou potenciais em um grupo de atores caracterizados por nós. O fluxo de informações nessa composição é influenciado pela extensão da rede e proximidade dos nós, tendendo a firmar relações de confiança entre aqueles que se mantêm próximos. As redes maiores em número de participantes tendem a ser mais dispersas e, por consequência, menos eficientes na transmissão da informação. $\mathrm{Na}$ rede em estudo, as ligações entre os nós (total de 1.837) representam uma média de 3,8 interações por participante, o que a classifica como rede de baixa densidade, tendo em vista o número de vazios estruturais constantes na matriz de $220 \times 220$, onde, teoricamente, seriam possíveis 48.400 ligações (Carrington et al., 2005).

Ao verificar a influência da densidade da rede relativamente às ligações (laços), sob a perspectiva de Granovetter (1973), pode-se constatar a existência de uma partição menor com conjunto de relações de laços fortes, resultando em uma rede densa, concomitante a um conjunto secundário que compõe uma sub-rede de dimensão espacial superior, porém caracterizado como rede de laços fracos de pouca densidade (Figura 2). Dessa forma, a caracterização geral da rede em análise pode ser considerada de baixa densidade, visto que foram observados $3,8 \%$ das ligações possíveis, identificando que a rede secundária, de baixa densidade, é resultante da pouca interação entre seus atores e o núcleo denso da rede.

Cabe salientar que é proporcional à densidade da rede a comunicação entre seus laços. A baixa densidade da rede, relacionada ao fator comunicação entre os nós, associa-se ao fato de que alguns nós possuem um número maior de ligações diretas com outros poucos nós, caso sejam comparados à maioria. Esses atores são importantes na transmissão das informações, pois sua exclusão do fluxo de informações pode provocar a disjunção das ligações e a consequente ruptura no processo de transmissão de informações em rede. Tal fato pode ocorrer quando há sobrecarga de informações em um único nó, resultante da baixa densidade da rede (Crossley et al., 2009).

O grau de coesão da rede é determinado pela variável reciprocidade, que indica a existência e o grau de reciprocidade na transferência de aprendizagem entre dois nós. $\mathrm{Na}$ rede composta de aquicultores, o índice de reciprocidade é de 22,014, ou seja, a cada cinco ligações apenas uma é recíproca, o que pode proporcionar baixa transferência de informações. Os nós que apresentam as maiores interações podem indicar mais participação em ações conjuntas (Sampaio et al., 2018).

A clusterização é resultante da probabilidade média de que existam relações diretas entre dois ou mais nós com um mesmo nó, apontada pela variável coeficiente de agrupamento. A sua constatação caracteriza o nível de densidade da rede. No caso análise, foi constatado que $35,1 \%$ da rede apresenta características de clusters.

A centralidade de intermediação visa determinar o quão centralizado é o grafo em torno de determinados nós. O item betweenness mede o grau em que o nó em análise se situa como elo entre outros nós que não se encontram diretamente ligados (Freeman, 2004). A centralidade de intermediação de um nó é calculada pela porcentagem de relações que intermedia, dando a esse nó status de influenciador, que pode atuar como "filtro" retentor do 
fluxo de informações. A presente rede apresenta alta centralidade $(2,625)$ em relativamente poucos nós (80). O índice de centralidade de proximidade da rede (centrality) é a variável mais explorada nas ARSs, pois busca identificar os atores centrais na estrutura geral da rede. A centralidade de um ator é igual à soma de suas conexões com outros atores. Ao considerar a totalidade da rede formada pelo grupo "Peixe de Rondônia", identificou-se o índice de centralidade de proximidade igual a 8,350, indicando que a maioria das distâncias entre os nós é significativa e, por essa razão, pode ocasionar efeito de retardo na transferência de informação.

A modularidade de 0,178 apurada na rede representa a medida de agrupamentos de nós, na qual os nós do grafo são classificados de acordo com suas conexões e suas densidades. Neste aspecto, Girvan e Newman (2002) defendem que a modularidade de grafos direcionados, como é o caso em análise, deve avaliar o número de conexões intragrupo em relação ao número esperado de ligações entre o mesmo grupo de vértices. Newman (2006) considera que redes com altos valores de modularidade apresentam conexões robustas entre os nós inseridos nos módulos, porém com conexões esparsas entre nós de diferentes módulos. No caso em representação, constatou-se que a conexão dos grupos intrarredes é consistente e pode ser observada nos quatro níveis de modularidade apontados pela análise, confirmando, visualmente, o nível de robustez que se dissipa de acordo com o nível menor de conexões, conforme representada na Tabela 4 e na Figura 3, respectivamente.

Tabela 4 - Distribuição da rede em quatro classes de modularidade.

\begin{tabular}{ccccc} 
Rede & Número de nós & Visível (\%) & Número de arestas & Visível (\%) \\
A- 4 classes & 220 & 100 & 1837 & 100 \\
B- 3 classes & 185 & 84,09 & 1342 & 73,05 \\
C- 2 classes & 136 & 61,82 & 813 & 44,42 \\
D- 1 classe & 80 & 36,36 & 390 & 21,23 \\
\hline
\end{tabular}

Fonte: elaboração própria com apoio do software Gephi (2019).

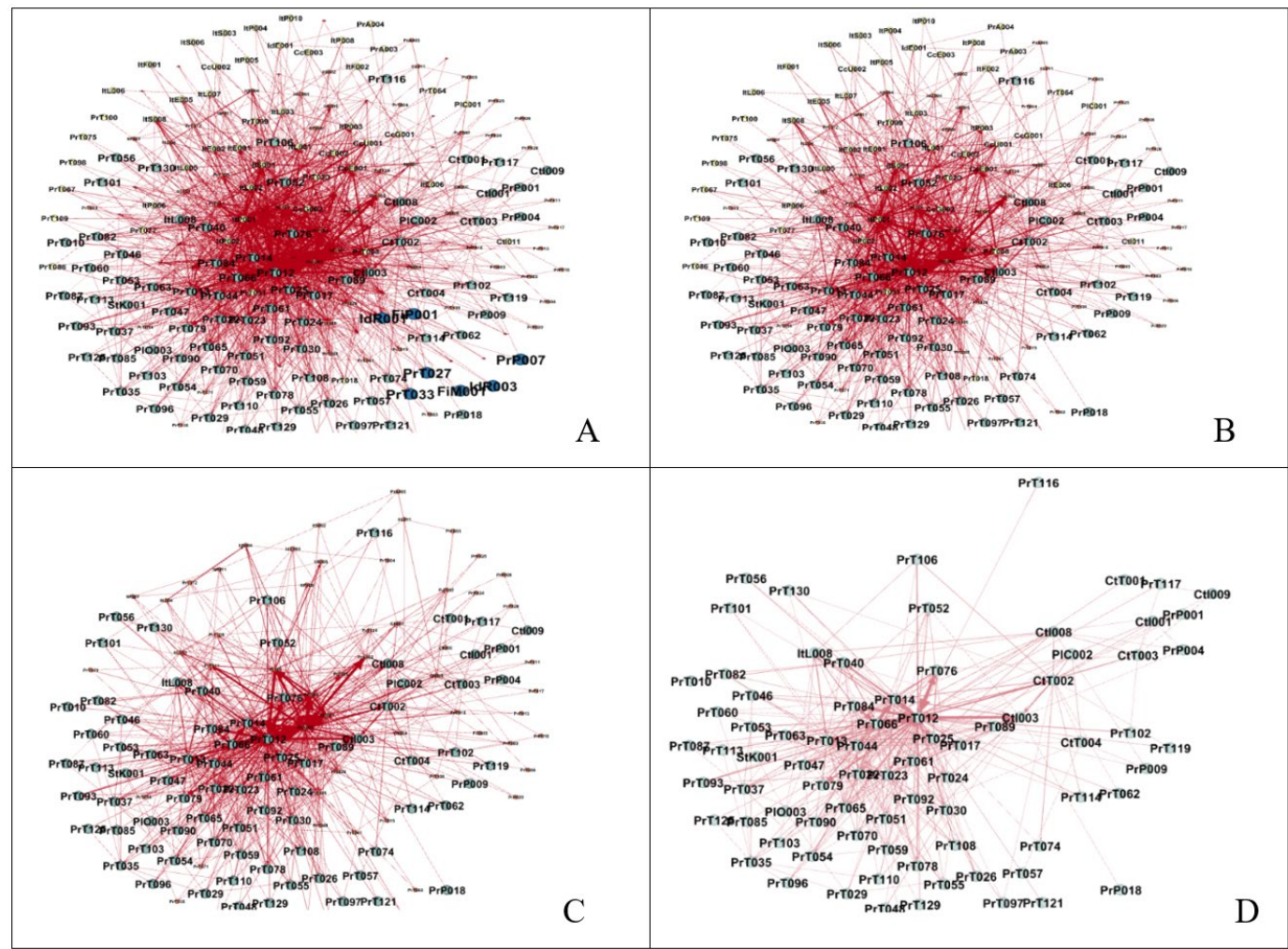

Figura 3 - Partição da rede em quatro classes de modularidade. Fonte: elaboração própria com o apoio do software Gephi (2019). 
Ao confrontar-se as quatro classes de modularidade geradas pela análise matemática do grafo, pode-se perceber o quão dispersas se apresentam as relações entre os diversos nós centralizadores demonstrados na rede total (Figura 3A). Nessa configuração, os 220 nós se relacionam por meio das 1.837 ligações de forma dispersa, com pouca densidade e frequência considerada baixa para os padrões de RSO, indicando que a rede pode não estar sendo condutora da partilha de informações entre os nós e, por consequência, pode limitar a disseminação de informações em rede (Dolinska \& D'Aquino, 2016).

A Figura 3B representa a rede total excluída de um grupo de nós que por si só não representa ganho no processo de troca de informações, porque 35 nós foram retirados da rede e, por isso, apresentam características de laços fracos com baixo grau de intermediação, tendo em vista as 495 ligações. Portanto, promove baixo impacto na transmissão de informações (Snijders et al., 2013). O mesmo processo se verifica na estrutura representada pela Figura 3C, a qual representa a retirada de 84 nós e 1.024 ligações da rede total. A esse respeito, observam-se números que apontam para uma participação mais ativa dos nós, indicando um grau médio de intermediação nas transmissões de informação na rede para essa classe.

A Figura 3D representa o centro da rede, visto que os 80 nós correspondentes a $36,36 \%$ da totalidade das conexões são responsáveis por $21,23 \%$ das ligações ocorridas, caracterizando-a por alta densidade e intermediação de ligações. Ademais, operam múltiplos contatos com nós que retratam setores estratégicos na rede demonstrada, a exemplo da representatividade de nós que configuram a classe dos produtores $(\mathrm{Pr})$, comerciantes $(\mathrm{Ct})$ e instituições (It). Há que se considerar que o predomínio de nós nessa classe é de produtores, seguidos por comerciantes e demais subcategorias .

\subsection{Análise de conteúdo}

Com base no corpus com 1.128 textos, 196.001 ocorrências, 5.798 segmentos de texto, 16.908 formas, 11.169 lemas, 5.294 hapax (2,70\% das ocorrências e $47,40 \%$ das formas), com média de ocorrências de 173,76 formas por texto, foram classificados 5.798 STs que compunham os temas ligados ao objeto deste estudo. Dos STs foi processado um total de 5.136 formas ativas, das quais 2.639 possuíam frequência maior que ou igual a 3 e com relação direta ao tema central de interesse da pesquisa.

Os textos com temas de interesse ligados à sustentabilidade e à inovação, ao serem inseridos no programa, possibilitaram a realização de análises de estatística multivariada, como a classificação hierárquica descendente (CHD), que realiza o fracionamento das formas mediante cálculos estatísticos do corpus de análise para chegar aos STs, que são classificados e ordenados em função das raízes lexicais que originam as palavras. Em decorrência da CHD, é obtida a análise fatorial de correspondência (AFC) como função interna dessa classificação, representado pelo plano cartesiano dos diferentes grupos de palavras sugerido pela CHD, 0 qual possibilita a verificação da expressividade de cada palavra junto ao conjunto de classes e ascensão aos STs visando ao conhecimento qualitativo dos dados (Salviati, 2017; Kami et al., 2016; Camargo \& Justo, 2013a).

A análise de similitude (AS) obtida com base nas formas encontradas nos conjuntos de STs que compõem o corpus do texto permite a visualização dos agrupamentos de formas lexicais como árvores de co-ocorrências e sua representação gráfica (Justo \& Camargo, 2014).

A análise da CHD possibilitou a visualização das formas que estiveram mais frequentes (média percentual) entre si e diferentes entre estas, gerando um dicionário de palavras por meio do método qui-quadrado $\left(\mathrm{Ch}^{2}\right)$. Assim, relacionam-se as formas significativas ao estudo dentre as que representaram valor superior a 3 ou $p<0,0001$, demonstradas pelo dendograma (Figura 4), resultantes da classificação hierárquica descendente, gerado pelo software, o qual indica a ligação das classes com temas de interesse (Ratinaud \& Marchand, 2012). 

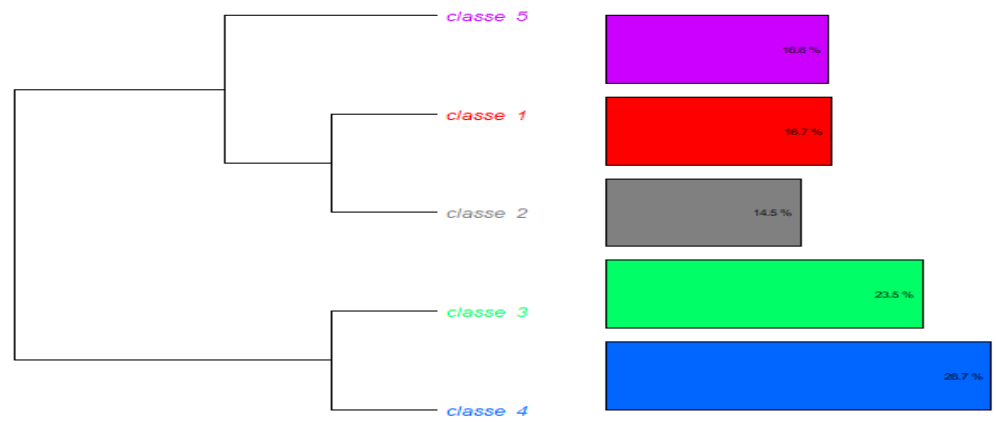

Figura 4 - Dendograma (CHD) dos temas relacionados à sustentabilidade. Fonte: elaboração própria com o apoio do software Iramuteq (2019).

Na Figura 4, o dendograma em forma de árvore representa a classificação hierárquica decrescente das formas, exposto em cinco clusters significativos, distintos e complementares entre si. Os clusters surgem divididos em dois grandes ramos. O ramo superior com três clusters associados às formas lexicais remete às discussões que envolvem a organização social do grupo: no cluster 1 (16,7\%), identifica-se a representação das ações de movimentação em rede dos atores do grupo e, no cluster 5 , as participações das instituições representantes de órgãos oficiais e privados $(16,6 \%)$.

No ramo inferior dividido em dois clusters, figuram o cluster 3 com 23,5\%, representando as formas que traduzem a preocupação com as questões efetivas de comercialização dos produtos, em paralelo com o cluster 4 , composto de formas diretamente ligadas à gestão da cadeia de valor na produção, produção e produtividade.

Para ilustrar a decomposição das classes em base lexical, apresenta-se, na Tabela 5, um breve resumo dos profiles (perfis) das classes.

Os perfis das classes, resumidamente, evidenciam a predominância das formas que geram conteúdo à discussão, remetendo o leitor ao conteúdo de interesse do grupo expresso naquela classe. A medida do $\mathrm{Ch}^{2}$ representa um teste de hipótese que compara a distribuição observada dos dados a uma distribuição esperada dos dados. No resumo, é apresentada a classificação crescente das formas e dos elementos significativos nas discussões de cada classe identificada pelo programa, denotando que os interventores nas discussões das classes são sempre as categorias ligadas aos assuntos em foco. As preocupações com inovações em processos produtivos e na cadeia de valor, com vistas à sustentabilidade, podem ser percebidas mesmo que indiretamente no contexto dos discursos.

A AS apoia-se na teoria dos grafos. Um grafo constitui o modelo matemático ideal para o estudo das relações entre objetos discretos de qualquer tipo e possibilita identificar as coocorrências entre as palavras e o seu resultado, além de apresentar indicações da conexidade entre as palavras, auxiliar na identificação da estrutura de um corpus textual, distinguindo também as partes comuns e as especificidades em função das variáveis ilustrativas (descritivas) identificadas na análise (Salviati, 2017; Camargo \& Justo, 2013b). A Figura 5 evidencia a representação dos grupos profissionais e as temáticas envolvidas.

A imagem representativa da Figura 5 agrupa em balões os temas de interesse em discussão e demonstra conexões entre os subgrupos que se complementam, mediante ligações por linhas com dimensões diferenciadas, cuja espessura indica o quão intensa é a força da vinculação entre as formas. O valor numérico das relações é representado pelo índice conectivo indicando o grau de conexidade entre as formas (Camargo \& Justo, 2013a), facilitando a análise visual das relações entre os clusters. 
Tabela 5 - Dendograma - Resumo dos perfis das classes

\begin{tabular}{|c|c|c|c|c|}
\hline Classes & Formas & $\mathrm{Ch}^{2}$ & Elementos significativos & $\mathrm{Ch}^{2}$ \\
\hline \multirow{6}{*}{ Classe 1} & Parabéns & 216,07 & Ação coletiva & 250,54 \\
\hline & Evento & 158,21 & Institucional & 49,5 \\
\hline & Participar & 137,13 & Ator instit. legislação - 9 & 45,26 \\
\hline & Reunião & 114,54 & Ator produtor terminador - 22 & 40,49 \\
\hline & Iniciativa & 106,94 & Ator instit. extensão e conh.- 1 & 39,25 \\
\hline & Piscicultura & 91,56 & $\begin{array}{l}\text { Ator instit. politicas públicas - } \\
1\end{array}$ & 21,19 \\
\hline \multirow{6}{*}{ Classe 2} & Grupo & 225,52 & Ator produtor terminador - 12 & 325,78 \\
\hline & Informação & 177,11 & Ação coletiva & 130,43 \\
\hline & Assunto & 118,24 & Normas do grupo & 63,34 \\
\hline & Resposta & 103,48 & Ator produtor terminador - 44 & 32,62 \\
\hline & Órgão & 95,29 & Ator instit. legislação - 1 & 19,8 \\
\hline & Resolver & 84,73 & Produtor & 19,68 \\
\hline \multirow{6}{*}{ Classe 3} & Preço & 473,04 & Mercado & 800,43 \\
\hline & Tambaqui & 266,68 & Produtor & 120,52 \\
\hline & Vender & 263,5 & Ator produtor terminador - 76 & 59,54 \\
\hline & Pagar & 261,64 & Ator produtor terminador - 14 & 52,94 \\
\hline & Ração & 225,7 & Ator produtor terminador - 84 & 45,62 \\
\hline & Peso & 142,12 & Ator produtor terminador - 66 & 32,53 \\
\hline \multirow{6}{*}{ Classe 4} & Mercado & 286,36 & Inovação na cadeia de valor & 126,34 \\
\hline & Produto & 234,54 & Nativos $\mathrm{x}$ exóticos & 117,47 \\
\hline & Qualidade & 151,73 & Certificação de origem & 64,33 \\
\hline & Nativo & 144,97 & Inovação de processo & 34,94 \\
\hline & Produção & 132,11 & Ator produtor terminador - 3 & 32,95 \\
\hline & Peixe & 107,76 & Pesquisa e desenvolvimento & 31,83 \\
\hline \multirow{6}{*}{ Classe 5} & Pesca & 502,44 & Institucional & 202 \\
\hline & Mapa & 338,57 & Ação coletiva & 151,04 \\
\hline & Aquicultura & 287,9 & Ator instit. associativismo -1 & 124,78 \\
\hline & Agricultura & 257,41 & Ator industrial - 1 & 104,04 \\
\hline & Secretaria & 251,89 & Ator instit. associativismo -3 & 89,26 \\
\hline & Ministério & 217,56 & Indústria & 75,94 \\
\hline
\end{tabular}

Fonte: elaboração própria com o apoio do software Iramuteq (2019). 


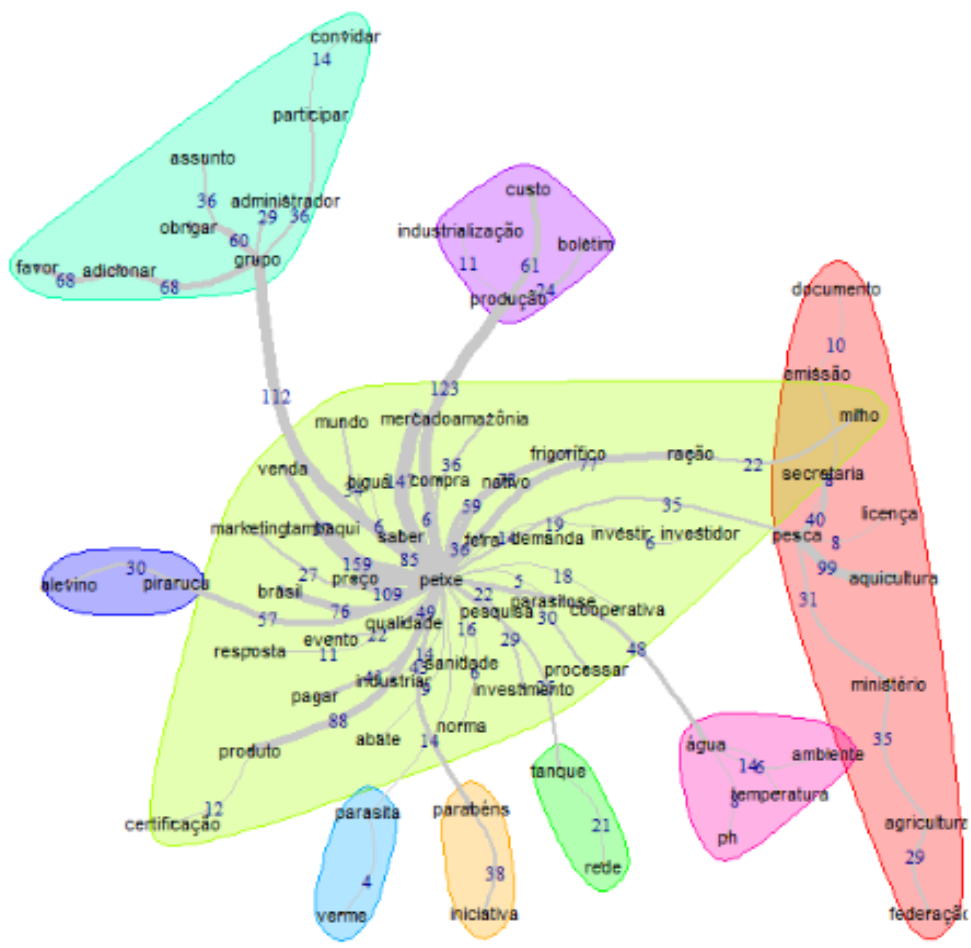

Figura 5 - Gráfico de AS "relação dos grupos profissionais e temas de interesse dos atores da rede". Fonte: elaboração própria com o apoio do software Iramuteq (2019).

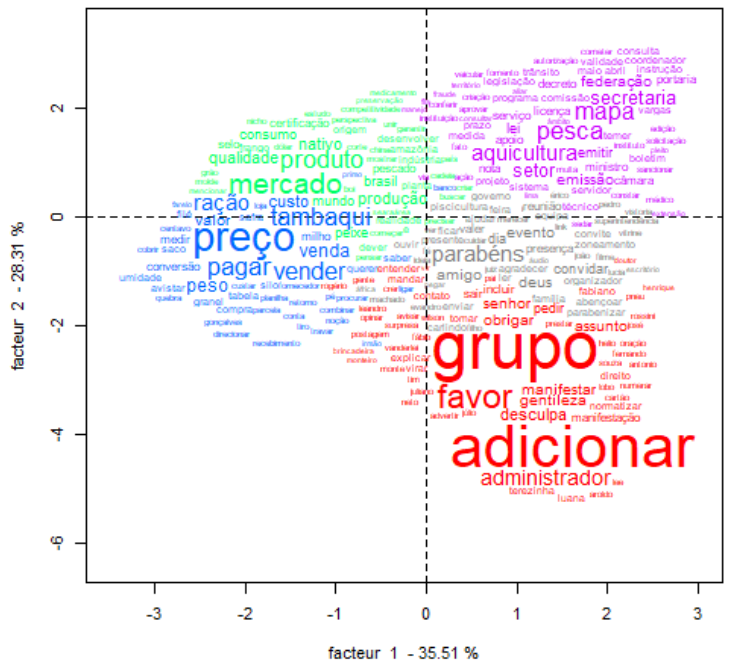

Figura 6 - AFC da CHD - As classes do dendograma pelo método de Reinert. Fonte: imagem gerada pelo software Iramuteq (2019).

A AS permitiu visualizar nos clusters a relação entre as formas ativas identificadas pelo programa na base comum da forma "peixe", onde aparecem todas as evidências e assuntos ligados à atividade, permitindo relacionar os distintos grupos de profissionais representados aos temas de interesse dos atores, bem como indicar seu índice de conectividade. As formas "grupo" e "produção", embora expressivos no contexto, aparecem em pontos distintos ao balão central, com índices de conectividade de 112 e 123, respectivamente, indicando sua importância. Os demais balões assessórios são complementares aos temas básicos de interesse. 
No plano cartesiano, pode-se observar proximidades e distanciamentos dos discursos analisados. A AFC, por exemplo, confirma e refina as interpretações realizadas na CHD ao ilustrar as relações de proximidade e oposição entre as classes, além de permitir a visualização global dos temas, grupos e atores e suas interações constituídas com base nos discursos. Assim, a AFC ilustrada pela Figura 6 representa a relação das diferentes palavras, as variáveis em análise, grupos e temas, aglutinadas nos quadrantes de referência, conforme a correspondência descendente entre estas (Kami et al., 2016).

A AFC confirma as interpretações realizadas na CHD, quando dispõe as cinco classes identificadas nos quadrantes com suas formas, correlações e grafadas em fontes com dimensões distintas, representativas do grau de interação no contexto, para propiciar visão global das relações dos elementos da rede (Salviati, 2017). Na presente análise, as formas que tratam das classes 1 e 2 estão dispostas no quadrante inferior direito, predominante e cumulativamente a outras formas, porém com mais ligação à classe 5 , focada nos aspectos institucionais, legais e regulatórios. No quadrante inferior esquerdo, sobressai a classe 3 relacionada aos temas 4 e 5 , sobre os quais a maioria dos atores de todos os grupos discute as questões relacionadas à produção e à produtividade, à comercialização do produto e à gestão da cadeia de valor.

\section{CONCLUSÕES}

No presente artigo, analisou-se a rede social "Peixe de Rondônia" que, ancorada no aplicativo de internet WhatsApp, foi idealizada para a comunicação entre aquicultores e organizações interessadas na aquicultura no centro-oeste da Amazônia brasileira. As mensagens analisadas, referentes ao período de 15 meses, demonstraram que a rede total (236 nós) se apresenta relativamente dispersa com baixa densidade, não sendo utilizada grande parte das ligações disponíveis para facilitar o compartilhamento de informações e aprendizagem coletiva.

A aplicação da metodologia de análise de redes demonstrou, por meio da medida de modularidade, que a rede possui métricas de destaque como mais coesão e centralidade em apenas uma de suas quatro partições (21,23\%). Além do mais, a análise dessa estrutura em especial demonstrou existir alto grau de coesão entre os nós que a compõem, caracterizandoa, assim, como uma possível comunidade digital de prática. Também se observou que os atores que compõem essa partição da rede (núcleo) são produtores terminadores em sua maioria, comerciantes e representantes de instituições ligadas à aquicultura.

A AC demonstrou, com base no total de 16.908 formas (palavras), que os atores expressam alguma consciência ecológica em suas afirmativas e proposições, quando expressam intenções de inovar no processo produtivo. Entretanto, identificou-se que não há alinhamento entre intenção e prática no que diz respeito ao tratamento adequado da água utilizada, do bem-estar animal nem do arraçoamento, visando limitar volumes de sedimentos nos tanques e outros elementos ligados à preservação dos mananciais hídricos. Os efluentes gerados e a densidade de peixes criados por hectare podem pôr em risco a sustentabilidade, quando se observa a pouca evidência de cuidado com os temas.

Tendo em vista os indicativos sobre a importância atribuída à disseminação de informações e a partilha de conhecimentos para o equilíbrio do sistema socioecológico da atividade aquícola, pode-se inferir que a rede social apresenta algumas características que a classificam como ferramenta de transmissão de informações e conhecimento técnico, assim como indicativos de agir na cadeia produtiva como elemento ativo para a governança da atividade. Observa-se, também, a ausência de ações indutoras a avanços efetivos ligados à sustentabilidade, uma vez que não foram identificadas atitudes reais que gerassem fortalecimento de seus elos com a finalidade de torná-la sustentável, na amplitude do termo, de forma que cabe o chamamento do necessário apoio técnico de órgãos e políticas públicas de extensão rural.

As interações na rede social analisada proporcionam, de modo geral, benefícios aos atores ativos, como aumento da proximidade e confiança entre os membros, mais interação e criação de conhecimento mediante troca de experiências, compartilhamento de informações técnicas, como alevinagem, arraçoamento, sistemas produtivos e de mercado 
como melhor momento para compra de insumos e venda dos produtos. A existência da rede proporcionou à atividade um empoderamento até então inexistente, resultante da multirrepresentatividade e da capilaridade dos atores, ao propiciar voz ativa nas discussões relacionadas às tomadas de decisão no contexto da aquicultura, indicando caminhos para assegurar a prosperidade do setor.

Neste prisma, a ARS combinada à AC produziu informações importantes para a identificação dos temas de interesse geral e dos atores-chave na provável comunidade digital de prática, àqueles com mais centralidade e poder de transferência de informações e conhecimento, indicando que são estes os mais importantes nós da rede e os interlocutores da aquicultura com os demais setores da sociedade.

Como limitação deste trabalho, registram-se as ações relacionadas à coleta de dados e a seu tratamento inicial, nos termos da AC, por se tratar de estudo pioneiro. Entretanto, a aplicação da ARS transcorreu satisfatoriamente, mesmo diante da dificuldade de identificação das ferramentas adequadas ao tratamento estatístico computacional dos dados em ambas os métodos. Para ampliar a consistência dos achados, sugerem-se estudos posteriores com diversificação das técnicas de coleta de dados, bem como abordagem às diferentes redes sociais, com a possibilidade de identificação de outros meios de organizações e/ou associações de produtores com potencial para aglutinar interesses e organizar ações em prol da sustentabilidade do SES representado pela aquicultura na região.

\section{REFERÊNCIAS}

Ahuja, G., Soda, G., \& Zaheer, A. (2012). The genesis and dynamics of organizational networks. Organization Science, 23(2), 434-448. http://dx.doi.org/10.1287/orsc.1110.0695

Bardin, L. (1977). Análise de conteúdo (Vol. 22). Recuperado em 18 de outubro de 2019, de http://books.google.com/books?id=AFpxPgAACAAJ\%5Cnhttp://cliente.argo.com.br/ mgos/analise_d e_conteudo_moraes.html\#_ftn1

Bert, T. M. (2007). Ecological and genetic implications of aquaculture activities. Springer.

Borgatti, S. P., Mehra, A., Brass, D. J., \& Labianca, G. (2009). Network analysis in the social sciences. Science, 323(5916), 892-895. http://dx.doi.org/10.1126/science.1165821

Borges, J. A. R., \& Lansink, A. G. J. M. (2016). Identifying psychological factors that determine cattle farmers' intention to use improved natural grassland. Journal of Environmental Psychology, 45, 89-96. http://dx.doi.org/10.1016/j.jenvp.2015.12.001

Boyd, D. M., \& Ellison, N. B. (2007). Social network sites: definition, history, and scholarship. Journal of Computer-Mediated Communication, 13(1), 210-230. http://dx.doi.org/10.1111/j.10836101.2007.00393.x

Brabo, M. F., Pereira, L. F. S., Santana, J. V. M., Campelo, D. A. V., \& Veras, G. C. (2016). Cenário atual da produção de pescado no mundo, no Brasil e no estado do Pará : ênfase na aquicultura. Acta of Fisheries and Aquatic Resources, 4(2), 50-58.

Bush, S. R. (2018). Understanding the potential of eco-certification in salmon and shrimp aquaculture value chains. Aquaculture, 493, 376-383. http://dx.doi.org/10.1016/j.aquaculture.2017.07.027

Camargo, B. V., \& Justo, A. M. (2013a). IRAMUTEQ: um software gratuito para análise de dados textuais. Temas em Psicologia, 21(2), 513-518. http://dx.doi.org/10.9788/TP2013.2-16

Camargo, B. V., \& Justo, A. M. (2013b). Tutorial para uso do software de análise textual IRAMUTEQ (p. 1-18). Laboratório de Picologia Social da Comunicação e Cognição, Universidade Federal de Santa Catarina.

Carrington, P. J., Scoot, J., Wasserman, S. (2005). Models and methods in social network analysis. http://dx.doi.org/10.1017/CBO9780511811395.

Crossley, N., Prell, C., \& Scott, J. (2009). Social network analysis: introduction to special edition. Methodological Innovations Online, 4(1), 1-5. http://dx.doi.org/10.1177/205979910900400101

Dolinska, A., \& D'Aquino, P. (2016). Farmers as agents in innovation systems. Empowering farmers for innovation through communities of practice. Agricultural Systems, 142, 122-130. http://dx.doi.org/10.1016/j.agsy.2015.11.009

European Comission. (2015). Observatório do mercado europeu dos produtos da pesca e da aquicultura (EUMOFA). Recuperado em 18 de outubro de 2019, de https://ec.europa.eu/fisheries/cfp/market/market_observatory_pt 
Fernandes, F. R., Cardoso, T. A., Capaverde, L. Z., \& Silva, H. F. N. (2016). Comunidades de Prática: uma revisão bibliográfica sistemática sobre casos de aplicação organizacional. AtoZ: Novas Práticas em Informação e Conhecimento, 5(1), 44-52. http://dx.doi.org/10.5380/atoz.v5i1.46691

Food and Agriculture Oraganization of the United Nations - FAO. (2016). The state of world fisheries and aquaculture. Rome.

Food and Agriculture Organization - FAO. (2018). FAO yearbook: fishery and aquaculture statistics 2016. Recuperado em 18 de outubro de 2019, de http://www.fao.org/3/a-i5716t.pdf

Freeman, L. C. (2004). The development of social network analysis: a study in the sociology of science (1218 p.). Vancouver: B.C. Empirical Press.

Girvan, M., \& Newman, M. E. J. (2002). Community structure in social and biological networks. Proceedings of the National Academy of Sciences of the United States of America, 99(12), 7821-7826. http://dx.doi.org/10.1073/pnas.122653799

Grabowicz, P. A., Ramasco, J. J., Moro, E., Pujol, J. M., \& Eguiluz, V. M. (2012). Social features of online networks: the strength of intermediary ties in online social media. PLoS One, 7(1), e29358. http://dx.doi.org/10.1371/journal.pone.0029358

Granovetter, M. S. (1973). The strength of weak ties (Vol. 1380). Chicago: Academic Press. http://dx.doi.org/10.1016/B978-0-12-442450-0.50025-0.

Ingram, J., Dwyer, J., Gaskell, P., Mills, J., \& Wolf, P. (2018). Reconceptualising translation in agricultural innovation: a co-translation approach to bring research knowledge and practice closer together. Land Use Policy, 70, 38-51. http://dx.doi.org/10.1016/j.landusepol.2017.10.013

Inman, A., Winter, M., Wheeler, R., Vrain, E., Lovett, A., Collins, A., Jones, I., Johnes, P., \& Cleasby, W. (2018). An exploration of individual, social and material factors influencing water pollution mitigation behaviours within the farming community. Land Use Policy, 70, 16-26. http://dx.doi.org/10.1016/j.landusepol.2017.09.042

Instituto Brasileiro de Geografia e Estatística - IBGE. (2019). Recuperado em 18 de outubro de 2019, de https://www.ibge.gov.br/

Justo, A. M., \& Camargo, B. V. (2014). Estudos qualitativos e o uso de softwares para análises lexicais. Caderno de Artigos: X SIAT \& I/ Serpro (2014), 37-54. Recuperado em 18 de outubro de 2019, de https://drive.google.com/file/d/0Bx09a4dcdTI6Y1czRIJIVI9VcHM/view

Kami, M. T. M., Larocca, L. M., Chaves, M. M. N., Lowen, I. M. V., Souza, V. M. P., \& Goto, D. Y. N. (2016). Working in the street clinic: use of IRAMUTEQ software on the support of qualitative research. Escola Anna Nery, 20(3), 1-5. http://dx.doi.org/10.5935/1414-8145.20160069

Maciel, R. G., Becker, C., \& Neske, M. Z. (2019). Os mercados da ovinocultura na pecuária familiar: proposições analíticas da Nova Sociologia Econômica. Revista de Economia e Sociologia Rural, 57(3), 396-412. http://dx.doi.org/10.1590/1806-9479.2019.178713

Marteleto, R. M. (2001). Análise de redes sociais: aplicação nos estudos de transferência da informação. Ciência da Informação, 30(1), 71-81. http://dx.doi.org/10.1590/S0100-19652001000100009

Marteleto, R. M. (2010). Redes sociais, mediação e apropriação de informações: situando campos, objetos e conceitos na pesquisa em Ciência da Informação. Earth and Planetary Science Letters, 22(3), 27-46.

McMillan, S. J. (2000). the microscope and the moving target: the challenge of applying content analysis to the World Wide Web. Journalism \& Mass Communication Quarterly, 77(1), 3-21.

Neuendorf, K. A., \& Skalski, P. D. (2010). Extending the utility of content analysis via the scientific method. In Social Science and Social Computing Workshop (pp. 1-34). University of Hawaii.

Newman, M. E. J. (2006). Modularity and community structure in networks. Proceedings of the National Academy of Sciences, 19(2), 56-66.

Oliveira, R. C. (2009). O panorama da aquicultura no Brasil: a prática com foco na sustentabilidade. Revista Intertox de Toxicologia, Risco Ambiental e Sociedade, 2(1), 71-89.

Ostrom, E. (2009). A general framework for analyzing sustainability of social-ecological systems. Science, $325,419-422$.

Ratinaud, P., \& Marchand, P. (2012). Application de la méthode ALCESTE aux gros corpus et stabilité des mondes lexicaux: analyse du «CableGate» avec IRAMUTEQ. In Actes des 11eme Journées Internationales d'Analyse Statistique des Données Textuelles (pp. 835-844).

Recuero, R. C. (2006). Comunidades em redes sociais na internet: proposta de tipologia baseada no fotolog (Tese de doutorado). Universidade Federal do Rio Grande do Sul, Porto Alegre. Recuperado em 18 de outubro de 2019, de www.lume.ufrgs.br/handle/10183/8614 
Recuero, R. C. (2014). Contribuições da análise de redes sociais para o estudo das redes sociais na Internet: o caso da hashtag \#Tamojuntodilma e \#CalaabocaDilma. Fronteiras Estudos Midiáticos, 16(2), 60-77. Recuperado em 18 de outubro de 2019, de http://www.revistas.unisinos.br/index.php/fronteiras/article/view/4860

Reinert, M. (2008). Mondes lexicaux stabilisés et analyse statistique de discours. Texte - Revue de Critique et de Theorie Litteraire.

Resende, E. K. (2009). Pesquisa em rede em aquicultura: bases tecnológicas para o desenvolvimento sustentável da aqüicultura no Brasil. Aquabrasil. Revista Brasileira de Zootecnia, 38(Suppl. 1), 52-57. http://dx.doi.org/10.1590/S1516-35982009001300006

Rieple, A., \& Snijders, S. (2018). The role of emotions in the choice to adopt, or resist, innovations by Irish dairy farmers. Journal of Business Research, 85, 23-31. http://dx.doi.org/10.1016/j.jbusres.2017.11.039

Rondônia. Secretaria de Estado da Agricultura - SEAGRI. (2019). Relatório anual de produção em Rondônia. SEAGRI.

Rosenfeld, A., Sina, S., Sarne, D., Avidov, O., \& Kraus, S. (2018). A study of Whatsapp usage patterns and prediction models without message content (pp. 1-24). MAFAT and the Israel Science Foundation. Recuperado em 18 de outubro de 2019, de http://arxiv.org/abs/1802.03393

Salviati, M. E. (2017). Manual do Aplicativo Iramuteq (p. 93). Universidade Nacional de Brasilia.

Sampaio, G. C., Marini, M. J., \& Santos, G. D. (2018). Capital social e ações conjuntas: um estudo de caso no arranjo produtivo de vinhos de altitude catarinense. Revista de Economia e Sociologia Rural, 56(4), 605-622. http://dx.doi.org/10.1590/1234-56781806-94790560404

Schneider, T., \& Sachs, S. (2017). The impact of stakeholder identities on value creation in issue-based stakeholder networks. Journal of Business Ethics, 144(1), 41-57. http://dx.doi.org/10.1007/s10551015-2845-4

Scott, W. R., \& Davis, G. F. (2016). Organizations and organizing: rational, natural and open systems perspectives.

Silva, C. A. (2019). Toolkit de tratamento de dados não numéricos em ciências sociais com software de livre acesso (Vol. 1). Lisboa.

Silva, M. E., \& Zen, A. C. (2014). O contexto base da inovação rumo à transição para a sustentabilidade: um ensaio sob uma perspectiva complexa. Revista Gestão \& Sustentabilidade Ambiental, 3(2), 61. http://dx.doi.org/10.19177/rgsa.v3e2201461-86

Skalski, P. D., \& Neuendorf, K. A. C. J. A. (2017). Content analysis in the interactive media age. http://dx.doi.org/10.4135/9781071802878.n7.

Snijders, T. A. B., Lomi, A., \& Torló, V. J. (2013). A model for the multiplex dynamics of two-mode and one-mode networks, with an application to employment preference, friendship, and advice. Social Networks, 35(2), 265-276. http://dx.doi.org/10.1016/j.socnet.2012.05.005

Soares, N., Pereira, M., Rodrigues, J., Oliveira, J., Rodrigues, A., \& Aguiar, R. (2018). Eficiência da biofiltragem por macrófitas aquáticas para a retomada da qualidade da água em uma piscicultura em Ouro Preto do Oeste - Rondônia. In Anais do I Simpósio em Ciencias Ambientais.

Souza-Silva, J. C., \& Schommer, P. C. (2008). A pesquisa em Comunidades de Prática: panorama atual e perspectivas futuras. Organizações \& Sociedade, 15(44), 105-127. http://dx.doi.org/10.1590/S198492302008000100006

Staevie, P. M. (2017). Interdisciplinaridade : contribuições para se pensar a Amazônia. Revista Latinoamericana de Estudios Avanzados, 2, 6-15.

Šūmane, S., Kunda, I., Knickel, K., Strauss, A., Tisenkopfs, T., Rios, I. I., Rivera, M., Chebach, T., \& Ashkenazy, A. (2018). Local and farmers' knowledge matters! How integrating informal and formal knowledge enhances sustainable and resilient agriculture. Journal of Rural Studies, 59, 232-241. http://dx.doi.org/10.1016/j.jrurstud.2017.01.020

Turner, J. A., Klerkx, L., White, T., Nelson, T., Everett-Hincks, J., MacKay, A., \& Botha, N. (2017). Unpacking systemic innovation capacity as strategic ambidexterity: how projects dynamically configure capabilities for agricultural innovation. Land Use Policy, 68, 503-523. http://dx.doi.org/10.1016/j.landusepol.2017.07.054

Uzzi, B. (1997). Social structure and competition in interfirm networks : the paradox of embeddedness. Administrative Science Quarterly, 42(1), 35-67. http://dx.doi.org/10.2307/2393808 
Varanda, M., Rego, R., Fontes, B., \& Eichner, K. (2012). A análise de redes sociais no mundo lusófono: contributos para o conhecimento de uma comunidade científica em desenvolvimento. Redes. Revista Hispana para el Análisis de Redes Sociales, 147-188.

Von Bertalanffy, L. (1977). Teoria geral de sistemas (p. 321). Editora Petrópolis.

Wasserman, S., \& Faust, K. (1994). Social network analysis: methods and applications. Cambridge: Cambridge University Press. http://dx.doi.org/10.1017/CBO9780511815478.

Zancan, C., Santos, P. C. F., \& Campos, V. O. (2012). As contribuições teóricas da Análise de Redes Sociais (Ars) aos estudos organizacionais. Revista Alcance, 19(1). Recuperado em 18 de outubro de 2019, de http://www6.univali.br/seer/index.php/ra/article/view/2166

Zattar, M., Marteleto, R. M., \& Varanda, M. P. (2017). Produção do conhecimento e prática informacional em campos e domínios inter e transdisciplinares: um recorte conceitual. In XVII ENANCIB. 